\title{
Enhancing L2 interaction in avatar-based virtual worlds: Student teachers' perceptions
}

\author{
Jun-Jie Tseng, Ya-Hsun Tsai \\ National Taiwan Normal University, Taiwan \\ Rih-Chang Chao \\ National Taichung University, Taiwan
}

\begin{abstract}
Three-dimensional (3-D) multi-user virtual environments (3-D MUVEs) have been used to provide language learners with realistic scenarios in which verbal and non-verbal interactions are simulated. However, little is known of the underlying factors that shape interaction in avatar-based virtual worlds. This study examined the perceptions of 38 student teachers of second language (L2) interaction in relation to the learning and teaching of Chinese as a foreign language (CFL) by using 3-D MUVEs. The data that were collected through reflection reports and interviews revealed that the key to the success of promoting L2 interaction may be contingent on the access to realistic scenarios and the presence of non-verbal cues. The participating teachers also offered suggestions regarding the future use of 3-D MUVEs to foster L2 interaction in the learning and teaching of CFL. Overall, the teachers considered this unique platform to be a promising venue where enhanced interaction may contribute to the understanding of target linguistic input, as well as the communication of the learners. This study has provided insight into the dynamic forces that mediate L2 interaction in 3-D MUVEs from the viewpoints of CFL teachers.
\end{abstract}

\section{Introduction}

The learning of Mandarin Chinese has gained prominence recently with the rapid rise of economic power in China, and the number of people who are learning Mandarin Chinese as a foreign language (CFL) is increasing. In particular, the number of K-12 school students in the United States who are learning CFL increased from 20,000 in 2005 to 60,000 in 2008 (Dobuzinskis, 2011). This increase indicates that more CFL courses are required in schools. In response to the global need of learning CFL, the Taiwanese government has dispatched CFL teachers to America and the rest of the world for CFL teaching. However, the number of CFL teachers may not be adequate at present and they are not made available to the learners in rural and remote areas. The Internet enables CFL learners to gain access to CFL courses without the constraints of space and time (Hampel \& Hauck, 2004). Therefore, an urgent need for CFL teaching and learning over the Internet is arising.

Distance language learning and teaching has progressed since 2000 (Henrichsen, 2001; White, 2003). With the advancement of web technology, the tools or platforms used for the delivery of distance learning courses range from email systems to course management systems such as WebCT and Moodle. As Warschauer (2000, p. 527) notes, distance education opens a new realm in which technology will be a "site of struggle" in determining the quality of learning opportunities. The current technology adopted in distance education predominantly involves computer-mediated communication (CMC), which allows for synchronous and asynchronous text-, audio-, or video-based communications. However, the impersonal nature of such communications may create difficulties for language learners who desire a sense of community and participation (Cooke-Plagwitz, 2008). This problem may be alleviated by the 3-D multiuser virtual environments (3-D MUVEs), which feature representational fidelity and learner interaction, two distinguishing characteristics that were identified by Dalgarno and Lee (2010). That is, 3-D MUVEs may provide language learners with realistic scenarios in which verbal and non-verbal interactions are simulated. The avatar-based interactions that are considered conducive to foreign language learning have been lacking in the contexts created by traditional CMC technologies (Vickers, 2009). The emergence of 3 -D virtual worlds brings forth new opportunities for language learners to shape online learning in the 21 st century.

Many authors have stressed the role of 3-D MUVEs in distance foreign language education, suggesting that the avatar-based virtual worlds provide favourable conditions for engaging language learners in 
social interaction (Allmendinger, 2010; Henderson, Huang, Grant, \& Henderson, 2012; Hew \& Cheung, 2010; Kan, Lan, Hsiao, \& Yang, 2010; Peterson, 2005, 2010, 2012; Varli, 2009). However, little research has yet been documented regarding the manner in which foreign language acquisition is fostered through interaction in this novel setting (Kan, et al., 2010; Peterson, 2008). A valuable area of study that warrants attention is to examine the underlying factors perceived by language teachers that can mediate second language (L2) interaction in 3-D MUVEs because the perspectives of the teachers are critical to the understanding of the complexities involved in L2 interaction (Tsui, 2001). This study adds to the body of knowledge by unravelling the thinking of language teachers pertaining to dynamic forces that affect L2 interaction in the context of 3-D MUVEs.

The affordances of 3-D MUVEs have led to a resurgence of interest in promoting L2 interaction in the context of distance foreign language education (Peterson, 2005; Petrakou, 2010). Though a number of researchers have reported that language teachers may encounter technological and instructional challenges when they carry out interactive activities with distance learners (Chen, 2010; Cheng, Zhan, \& Tsai, 2010; Ellis \& Anderson, 2011), there is little conclusive evidence that attests to the ways the teachers enhance L2 interaction in 3-D virtual worlds. To fill the gap in the literature, the present study helped the participating teachers address this problem by adopting team teaching, in which the teachers might find ways to enhance avatar-based interaction through commenting on the instructions of each other, sharing their ideas on handling problems, and appreciating the use of alternative teaching techniques (Richards \& Farrell, 2005). The results gained from this study could provide insights into how L2 interaction can be fostered in 3-D MUVEs from the viewpoints of CFL teachers.

The research rationales given above guided the researchers to answer the research questions that follow:

- What were the perceived factors that affected L2 interaction involved in the learning and teaching of CFL via 3-D MUVEs?

- What were the suggestions of CFL teachers with regard to enhancing L2 interaction in 3-D MUVEs?

\section{Literature review}

This section consists of the following: (a) theoretical framework, (b) computer-mediated interaction, and (c) the perceptions of teachers of L2 interaction involved in 3-D MUVEs.

\section{Theoretical framework}

This study was informed by the following two theories: cognitive second language acquisition (SLA) theory and sociocultural theory. Cognitive SLA theory is used as a framework for investigating computerassisted language learning (Chapelle, 1997). From a cognitive perspective, the computer can provide the learners not only with linguistic input, but also with a platform for interaction. It also offers them the opportunity to output the target language (Hampel, 2003). The acquisition of the target language is considered as the product of processing linguistic input and output (Ellis, 2000). The second theory underpinning this study is sociocultural theory, which assumes that learning is constituted by the interactions of learners with cultural, societal and institutional practices. Sociocultural theory provides a theoretical framework for understanding CMC, which is claimed to offer favourable conditions for interactive, situated learning (Hampel, 2003). Language communication is depicted as an embodied and situated activity.

Cognitive SLA theory and sociocultural theory were used to inform this study on the manner in which a foreign language may be learned in 3-D MUVEs. From a cognitive perspective, 3-D MUVEs were used to provide vocabulary input illustrated by scenario objects; and from a sociocultural perspective, the virtual worlds were used to provide realistic settings simulated for role playing that involved scenariobased tasks completed by the learners taking on any roles that might differ from their real-life roles. In this regard, linguistic knowledge is not objective, but is constructed and experienced through the body and senses to some learners (Svensson, 2003). 


\section{Computer-mediated interaction}

Interaction is a crucial process in which foreign language learners learn to develop linguistic knowledge and communicative competence. It is necessary to provide learners with opportunities to practice the target language through interaction under naturalistic or classroom-instructed conditions (Holliday, 2007). Interaction may be enhanced by various computer technologies that can create new social and electronic spaces to support social interaction synchronously and asynchronously (Khalsa, Maloney-Krichmar, \& Peyton, 2007). According to Chapelle (2005), computer-mediated interaction may occur in the following three conditions: between people, between a person and a computer, and within the mind of the person. By focusing on the first two types of interaction, this study provides CFL learners with the opportunity to obtain enhanced input between themselves and the computer, as well as to negotiate meaning among themselves (Long, 1996).

Interaction between the learners and the computer

The computer is able to contribute to comprehension in terms of the interaction between the learners and the computer. The target language must be enhanced to provide comprehensible input to the learners (Chapelle, 2005; Holliday, 2007). Since comprehension involves not only processing linguistic code but also activating the knowledge of students about the world, language learning activities should provide the contexts that can activate the world knowledge of learners beyond linguistic knowledge (Hadley, 2001). Thus, comprehensible input should include linguistic, extra linguistic, and contextual information that are associated with real life scenarios (Grant \& Huang, 2010). Such needs may be met in 3-D MUVEs, which provide a type of virtual environment that simulates realistic contexts in which L2 learners can immerse themselves for linguistic exposure (Coleman, Hickman, \& Wrege, 2007).

CMC technologies have been utilized to promote the teaching and learning of foreign and second languages, such as email, discussion forum, text chat, voice chat, and multi-user object-oriented (MOO ). In particular, MOO, a precursor of 3-D MUVEs, provides content-rich worlds where the learners can create personally meaningful artefacts (Emde, Schneider, \& Kötter, 2001; Peterson, 2001). However, different from the virtual worlds that are text-based, 3-D MUVEs are claimed to facilitate language learning by engaging the learners in a wide range of realistic scenarios simulated by 3-D technology. In this sense, language learning involves sensory experiences (Dalgarno \& Lee, 2010; Hew \& Cheung, 2010). Three-dimensional MUVEs may provide experiential spaces in which the learners can interact with scenario objects associated with linguistic input (for example, artefacts simulated from realistic living environments) (Coleman, et al., 2007; Grant \& Huang, 2010).

In this regard, Liu (2010) demonstrated that learning materials may be simulated in a 3-D virtual world such as Second Life. For example, in a CFL class, when the learners are talking about diet, they can be shown a variety of dishes that are represented in 3-D forms while being exposed to linguistic information associated with the foods, such as Chinese characters, audio pronunciations, and Pinyin. Virtual worlds may enable the learners to virtually immerse themselves in particular situated settings where they can sense linguistic information rather than just reading text (Chow, Andrews, \& Trueman, 2007).

\section{Interaction between the learners and the teacher}

To acquire the target language, the learners may also practice the language by interacting with native and non-native speakers of the contact language over networked computers on the Internet (Holliday, 2007; Khalsa, et al., 2007). Traditional CMC tools, such as email, forum, and text chat, are used to provide the learners with contexts for authentic communication. However, these types of text-based CMC media may lead to some degree of social presence, that is, a sense of the participants being physically present at a particular place (Short, Williams, \& Christie, 1976). A reduced social presence may occur because textbased communication does not convey non-verbal cues such as gestures, facial expressions, and other types of body language (Khalsa, et al., 2007). To address this problem, 3-D MUVEs may be in a favourable position to promote a sense of social presence because avatars can display a number of nonverbal cues that are not present in general CMC (Allmendinger, 2010; Peterson, 2008; Svensson, 2003). For example, gestures and facial expressions displayed by avatars may carry non-verbal information that indicates what the users are acting or performing for particular communicative purposes.

Peterson (2006) investigated the interaction of 24 intermediate-level English as a foreign language undergraduate students who participated in task-based CMC in avatar-based virtual worlds. The majority 
of the students were found to have used the non-verbal communicative features of their avatars. In particular, the avatars enabled them to wave to each other to attract attention and to display emotional responses such as joy.

Figure 1 illustrates the literature reviewed above to provide an understanding of L2 interaction in 3-D MUVEs. It can be seen that 3-D MUVEs can afford L2 learners to engage in L2 interaction in a manner that is different from that of general CMC tools. More specifically, the learners can gain a better understanding of linguistic input through experiencing realistic scenarios, and they can also facilitate their communication through avatar gestures. Much has been said about the unique characteristics of 3-D MUVEs in relation to L2 interaction, but questions remain regarding how L2 teachers perceive this technology as a tool that can enhance L2 interaction in distance foreign language education.

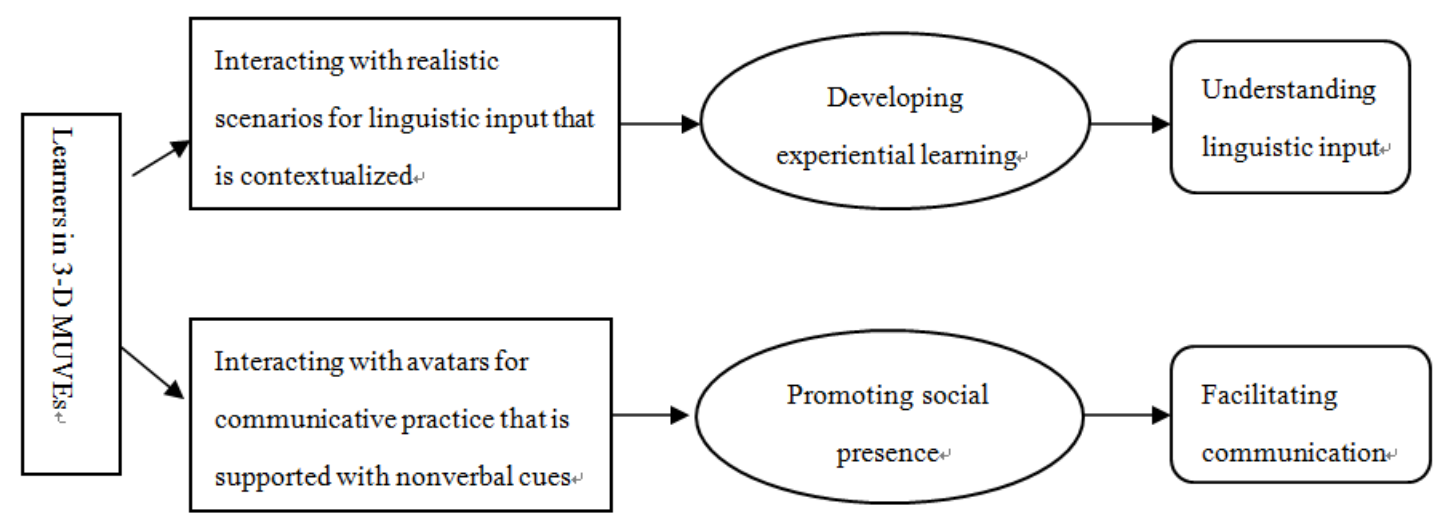

Figure 1. L2 interaction in 3-D MUVEs.

\section{Teachers' perceptions of L2 interaction involved in 3-D MUVEs}

Three-dimensional MUVEs have attracted notable interest from researchers and practitioners, including foreign language educators, since its inception a decade ago (Clark, 2009; Cooke-Plagwitz, 2008, 2009; Kuriscak \& Luke, 2009). The application of this technology to foreign language learning and teaching is in the pilot phase. However, the review of the following studies enables the investigation of the thinking of L2 teachers regarding the complexities of L2 interaction in 3-D MUVEs. Varli (2009) conducted research on five EFL teachers who designed course content and delivered it in Second Life. The virtual setting was perceived to support the sociocultural paradigm evident in the teaching and learning activities that the teachers conducted. Cheng et al. (2010) reported a cooperative CFL project between Taiwan and the United States. Sixty-five pre-service teachers, who were divided into thirteen groups, were assigned to teach thirteen American students. One of the quantitative findings indicated a significant increase in the number of the participating teachers who believed that virtual environments created in 3-D MUVEs like Second Life provided favourable conditions for language communication. Another study undertaken by Kan et al. (2010) investigated avatar-context interaction. Two Chinese teachers co-taught eight beginner students of Chinese through Second Life. As a result, the teachers thought that there was room for improvement in regard to the gestures and movements displayed by the avatars. For example, gestures such as pointing to, taking out, and showing an object were unavailable to the teachers when they wanted to display non-verbal cues for facilitating communication with the learners. Also, the avatars were unable to demonstrate a clear mouth motion for teaching Chinese pronunciation. In addition, they thought that the learners might experience difficulty in understanding the cross-cultural messages that were conveyed through particular scenario objects. For example, CFL beginners had a problem understanding particular Chinese lucky symbols, such as bats standing for good luck and deer representing prosperity.

Research on the teaching and learning of second or foreign languages in 3-D MUVEs is still in its infancy because of the technical skills, cost, and time required in creating the simulated environments (Coleman, et al., 2007; Dalgarno \& Lee, 2010; Xie, 2010). Even less has been explored on how L2 teachers address problems or difficulties associated with L2 interaction when they carry out instructional activities in 3-D MUVEs. It is hoped that the findings in this regard gained in the present study can shed light on the ways to enhance L2 interaction in avatar-based virtual worlds. 


\section{Methodology}

This section includes descriptions of (a) participants, (b) setting and procedures, and (c) data collection and analysis.

\section{Participants}

Thirty-eight participants, who were students of the Applied Chinese Department of a national university in northern Taiwan, were invited to participate in the project focused on practicing the teaching of CFL via 3-D MUVEs. Three of the student teachers were male and 35 were female. Their ages ranged from 19 to 21 years old. All of them were native speakers of Mandarin Chinese and were learning to teach CFL. The recruitment of these young people growing up in the digital world was out of consideration for their tendency to embrace new technology. In addition, if they acquire teaching skills associated with distance foreign language education, they may be equipped for more career opportunities in the future. To ensure their readiness for this project, they were trained to develop information capabilities related to the teaching of CFL through the E-training Program for Mandarin Teaching Professionals, which was organized by Ministry of Education in Taiwan.

A total of $43 \mathrm{CFL}$ learners were recruited to this project through the Overseas Compatriot Affairs Commission, Taiwan, which aims to promote the teaching and learning of CFL abroad. The participants included 26 males and 17 females, aged between 15 and 30 years old. They were located in 13 different countries, that is, Korea, Vietnam, the Philippines, Malaysia, Indonesia, Australia, Denmark, Germany, Poland, England, Spain, America, and Brazil. They had been requested to possess general computer skills such as surfing the Internet and installing a microphone by the time they started learning in the project. They were taught to use 3-D MUVEs designed for the study. These learners rated their Chinese proficiency at the beginning level, except one low-intermediate learner and two intermediate learners. Learners of this level were thought to be motivated to learn CFL in realistic scenarios simulated in 3-D MUVEs (Chen, 2010; Cooke-Plagwitz, 2008, 2009; Henderson, et al., 2012). The learners could choose to join more than one pair of teachers for tutoring. The Appendix displays information regarding the number of tutors and learners in each grouping, as well as the proficiency level of these learners.

\section{Setting and procedures}

The entire project was conducted on Second Classroom, which is a 3-D MUVE that was created by the Department of Digital Education under the Institute for Information Industry in Taiwan. This virtual platform was hosted on a social computing network with a high-speed broadband connection; therefore, the graphics loaded through the 3-D avatars and objects were clearly displayed without any observable lags. Similar to Second Life, Second Classroom provided realistic scenarios in which the 38 student teachers and the 43 learners could interact with each other through avatars. The 3-D virtual worlds were co-designed by the Department of Digital Education and the Department of Applied Chinese that the researchers are affiliated to, and included four settings which were the airport, the hotel, the restaurant, and the mass rapid transportation system. Figure 2 illustrates the interface of Second Classroom, in which the teachers conducted their teaching through the use of the microphone, text chat, and PowerPoint slides. The student teachers received training on operating Second Classroom, such as installing microphones, playing avatars, and uploading teaching materials.

The 38 student teachers were divided into 19 pairs. They were required to carry out team teaching, which involved a cycle of team planning, team tutoring, and team follow-up (Richards \& Farrell, 2005). The benefit of team teaching was to allow the teachers to learn from watching how the other taught the class and to complement each other. Thus, it was thought that team teaching could enable the teachers to develop knowledge and skills associated with enhancing L2 interaction.

Prior to online tutoring sessions, the student teachers were required to write lesson plans for particular topics that were based on the four simulated scenarios. In this case, the instructional topics included asking for directions, checking into a hotel, ordering food, boarding mass rapid transportation, and various other related topics. In addition, they created teaching materials with PowerPoint that could be uploaded into Second Classroom. 


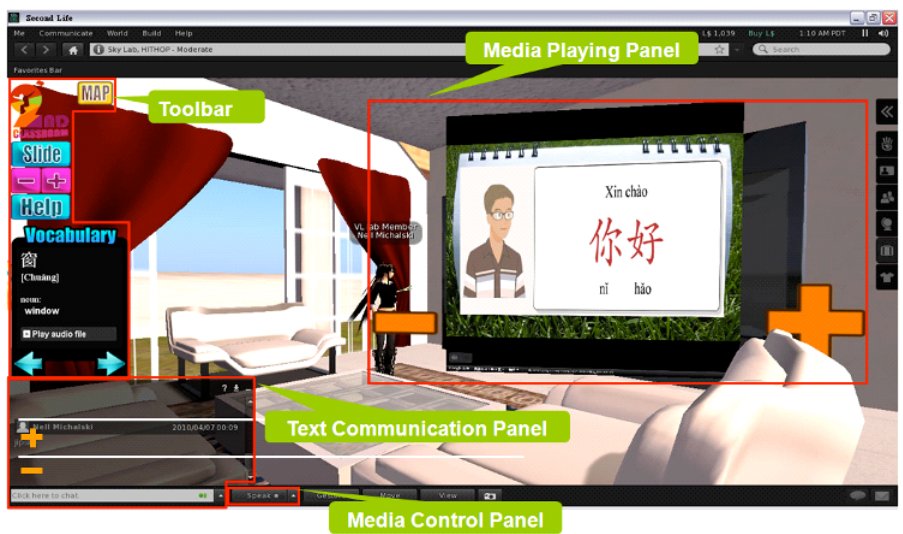

Figure 2. The interface of Second Classroom.

Each pair of the participating teachers was in charge of 12 tutoring sessions, each of which lasted for two hours in which 1-6 participants were learning. Each pair tutored for a total of 24 hours. When the tutoring sessions began, the paired teachers and their assigned students would simultaneously log on to Second Classroom and communicate with each other through the microphone and the speaker. The paired teachers conducted team teaching. While one teacher was teaching, the other teacher would offer technical and instructional support and make observations of peer instructions.

The team teaching involved learning pronunciation, vocabulary, and topic-based dialogues that highlighted expressions and sentence patterns since most of the students were beginning learners. The students learned vocabulary words by clicking on scenario objects for these words (traditional Chinese characters, simplified Chinese characters, English words, and Pinyin), pronunciation, and example sentences, as displayed in Figure 3. In addition, the students were asked to play roles in situated settings that could not be replicated in a traditional classroom, as shown in Figure 4. The learners could receive immediate feedback from the student teachers on their linguistic performances during the tutoring sessions.

After each online teaching session, the paired teachers would meet to review previous teaching sessions. In particular, they were told to elaborate on technical and instructional aspects of gains and problems in relation to L2 interaction in 3-D MUVEs. The team follow-ups served to guide their next teaching sessions.

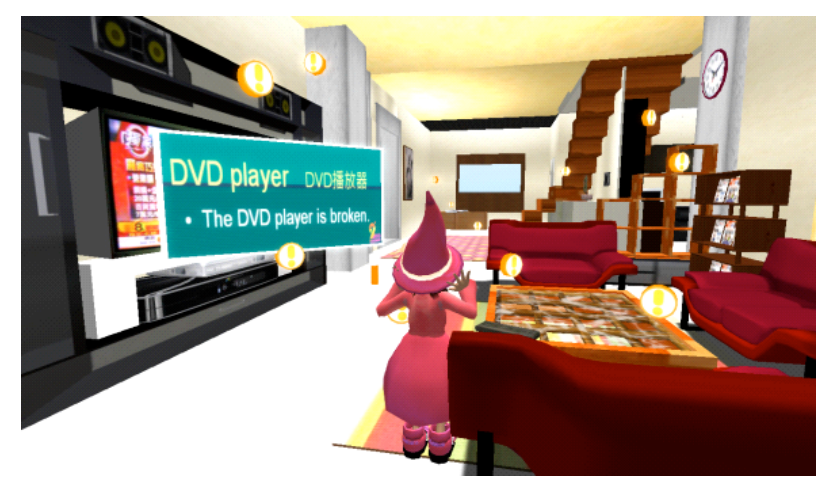

Figure 3. The vocabulary information associated with scenario objects. 


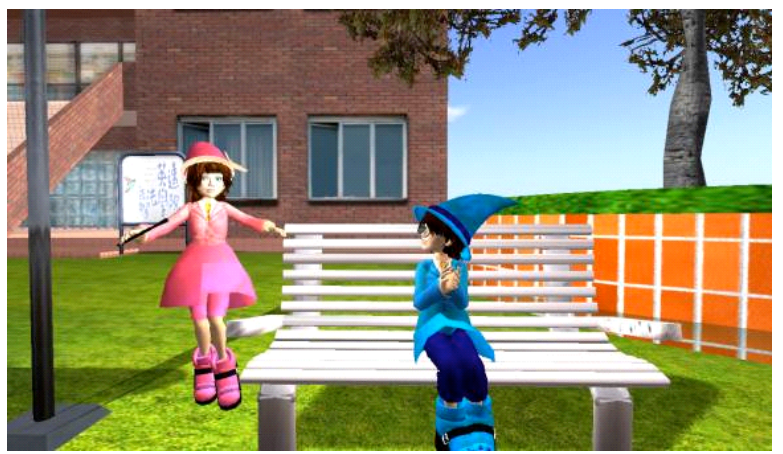

Figure 4. Role playing through avatars.

\section{Data collection and analysis}

To understand the perceptions of student teachers of L2 interactions in 3-D MUVEs, a retrospective approach was used to examine their teaching experiences specific to enhancing L2 interaction in Second Classroom. The pairs of student teachers were asked to co-author a reflection report at the end of the project. In particular, special attention was paid to their reflections that involved factors mediating L2 interaction and suggestions facilitating L2 interaction. A total of 19 written reports were collected.

Another tool to collect data was interviewing, which was used to complement reflection reports. While the first author was reading the written reports, he would particularly highlight the parts that were unclear or lacked evidence. Then, in interviewing the 19 pairs of teachers, he would ask for their clarifications and seek their confirmations. In addition, the first author tried to form a complete picture of L2 interaction in 3-D MUVEs by raising particular questions that might have not been answered in their reflection reports. This aspect of interview was guided by the questions that follow. Taking around 30 minutes, each interview with individual pairs was audio-recorded and transcribed verbatim for data analysis.

- How did you interact with the learners in Second Classroom?

- Did the learners make use of the scenarios? In what way?

- What do you think about L2 interactions taking place in Second Classroom?

- What problems did you encounter while you were interacting with the learners in Second Classroom?

- What suggestions would you make with regard to enhancing L2 interaction over Second Classroom?

With regard to data analysis, a qualitative approach was adopted to seek patterns out of the data inductively (Silverman, 2000). The first author and the second author were involved in coding data and generating patterns. The authors met prior to the data analysis to build the coding principles and to reach a consensus on coding criteria. The coding process was guided by Chapelle's (2005) model of computermediated interaction, particularly between the learners and the computer and between the learners and the teacher. When the two authors coded the data individually, they searched for particular chunks of reflection reports and interview transcriptions--passages that represented the thoughts of particular student teachers that were related to the L2 interactions. Subsequently the authors labelled them with specific terms. The coding labels were compared and contrasted to generate the coding patterns. After the coding labels and patterns were identified, the two authors met again to discuss the coding results. If any discrepancies in the coding labels and patterns were found, they modified them for unity and consistency.

The quoted statements were translated from Mandarin Chinese to English to present the data in the Results section. 


\section{Results}

The results are presented according to the research questions.

\section{What were the perceived factors that affected L2 interaction involved in the learning and teaching of CFL via 3-D MUVEs?}

L2 interaction in 3-D MUVEs was perceived to be contingent on access to realistic scenarios as well as on the presence of non-verbal cues.

Access to realistic scenarios

The major factor that is associated with L2 interaction in 3-D MUVEs is the access to realistic scenarios. A number of the student teachers thought that if the realistic scenarios were appropriately incorporated into the instructional contents, the opportunities for interaction would increase between the distance learners and the teacher. The predominant benefit of applying the realistic scenarios was to provide social contexts in which the target words and teaching topics were simulated. A meaningful interaction between the distance learners and the teacher may be facilitated by such simulated contexts. Pair 3 illustrated this advantage with the following statement:

We felt better in the teaching of asking for directions. Because it was close to Christmas, the scenarios for this topic included a post office and a 7-11 convenience store. Over there, mail box, the sign of 7-11 convenience store, and traffic lights could be seen. The color in common among them was the color of Christmas. We had more interactions by talking about various kinds of colors. (Reflection report)

As several of the student teachers reported, the scenarios may provide the distance learners with opportunities to conceptualize the target words and to associate the target words with real-world contexts. Pair 16 provided the following example of learners interacting with scenario objects for contextualizing the target vocabulary words:

For example, there was a painting of a naked girl hanging at the hotel. Hua (in Pinyin) was the vocabulary word we previously taught. She said later that when she sees the character of Hua, she would think of the painting of a naked girl. Then, she would come to understand that that is a painting. ... When teaching about places like the restaurant and the computer room, she said: This is the restaurant. (Reflection report)

In addition, the learners may interact with the scenarios by immersing themselves in simulated locations. As many of the participating teachers described, they may implement role-playing in which the learners are provided with an opportunity to speak in the target language. Such telepresence allowed the teachers to take their students to several locations, such as airports and restaurants. This convenience is not possible in traditional classrooms. For example, Pair 16 supported the idea of engaging the learners in realistic scenarios for linguistic production, according to the following statement:

Because the scenario at the restaurant involved a bar counter, she sat next to it and asked us for wine. She was a very lively person, so teaching her in class was pleasant. (Interview)

The presence of non-verbal cues

A number of the student teachers experienced difficulty in receiving immediate, visible feedback from the learners because they were unable to maintain face-to-face contact with the distance learners. Consequently, they felt that they would lose control over the learners and be unable to ascertain whether the learners were attentive to the class and whether they gained an understanding of the topics of the lecture. For example, Pair 7 confirmed that this problem was encountered in their distance teaching experiences with the following statement:

Because the students' facial expressions and body language were not visible in 3-D MUVEs, it was hard to determine whether they comprehended. (Interview) 
The student teachers experienced difficulty in teaching in the target language because they were unable to express non-verbal cues such as facial expressions and body language. Pair 5 confirmed this instructional difficulty with the following statement:

The teacher lacked the advantage of facial expressions and body language in teaching. This would cause an effect on the frequency the teacher utilized the target language, Mandarin Chinese. Instead, more explanations in English would be needed. It was hard to create a learning environment where the target language is exclusively used. This was the difficulty we had trouble getting used to. (Reflection report)

Another aspect of non-verbal cues highlighted by the teachers involved paralanguage. The communication through the use of a microphone was the main type of interaction between the student teachers and the distance learners. Some of the student teachers thought that they could have enhanced their speaking voices to attract the attention of the learners in class. The optimal manner to achieve this was to incorporate more emotion into the online teaching, as indicated by the following statement of Pair 11:

In fact, online teaching is supposed to be incorporated with more feelings because the teacher is unable to interact face to face with students and meanings and tones can be transmitted only through voices. If the teacher is not passionate, students' learning interest would decrease. (Reflection report)

\section{What were the student teachers' suggestions with regard to fostering interaction in 3-D MUVEs?}

The suggestions offered by the teachers include (a) enabling access to more scenario objects and (b) creating scenarios appropriate for beginners.

\section{Enabling access to more scenario objects}

Many of the student teachers suggested that more scenario objects should be made accessible and interactive to the learners. If the learners gained admission to the buildings on the streets, the learners may have experienced the feeling of strolling around the streets. When they enter particular buildings, they will have an opportunity to acquaint themselves with a number of the items or goods on display. As such, they may have felt excited when they interacted with the clickable objects. In particular, Pair 15 emphasized the need for accessible and interactive scenario objects with the following statement:

In the aspect of scenarios, some interactive objects can be added in conjunction with lesson plans so that students can practice with them on the spot. If some scenarios can be put into actual use, teaching will be more effective. For example, if ticket machines like those in real-world life are operational, students can practice on them immediately. (Reflection report)

\section{Creating scenarios appropriate for the beginners}

When planning the lessons based on the scenarios, some of the student teachers found that most of the scenarios would be difficult to beginners of CFL. For example, it was difficult for them to produce teaching materials that could cater to the level of the learners in scenarios such as the airport and the hotel. The teachers thought that the beginning learners may not be able to perform a role-play under such contexts. The vocabulary words that were associated with the scenarios may not have been appropriate for these learners, as Pair 14 stated below:

Most of the students were beginners, so the contents of the lessons must be easy and practical. However, words related to some scenarios were too difficult to the beginning students. Therefore, it was a bit hard to design the lessons. (Interview) 


\section{Discussion}

In relation to addressing interaction in Second Classroom, special attention is paid to increasing the opportunity to interact with the realistic scenarios and enhancing non-verbal communications.

\section{Increasing the opportunity to interact with the realistic scenarios}

The student teachers thought that the realistic scenarios afforded the learners the opportunity to interact with their peers and their teacher. The learners were thought to be able to practice the target language by immersing themselves in simulated contexts, such as asking for directions on the street and ordering drinks at the bar of the restaurant. As such, the learners were provided with "a sense of place,..." which "... makes learning, and indeed socializing in a virtual world, a more 'human' experience than many other online environments." (Stanley, as cited in Erard, 2007). The results suggest that the simulated contexts created by 3-D MUVEs appear to elicit a certain degree of participation and interaction, as suggested by Peterson (2010).

Furthermore, the teachers believed that linguistic input may be enhanced by the objects and artefacts displayed in 3-D MUVEs. They suggested that interaction may be promoted if more objects are clickable. The interactive objects were thought to facilitate the comprehension of the target vocabulary words. This perception is consistent with Liu's (2010) claim that objects associated with particular words or concepts can be simulated to help the learners better understand the target linguistic input. This also echoes with the words of Grant and Huang (2010) that 3-D MUVEs may provide a unique opportunity for creating an environment that is rich in "comprehensible input."

However, as the teachers pointed out, they had difficulty designing lessons based on such realistic scenarios as the airport and the hotel for the beginning learners. To overcome this problem, some consideration could be given to the following three ways: (a) The learners could initially make use of Pinyin to facilitate their understanding of certain difficult vocabulary words associated with particular scenario objects; (b) The student teachers could engage in careful instructional design that may come up with a range of appropriate learning activities, a training session that should be highlighted in teacher development activities such as team teaching adopted in the present study; (c) The teaching practitioners could discuss with the designers of 3-D MUVEs beforehand so as to reach an agreement on the appropriateness of scenarios and objects for students with certain level of language proficiency.

In summary, 3-D MUVEs can provide the learners with simulated contexts in which they are able to experience linguistic information rather than just reading texts, as argued by Chow et al. (2007). Such experiential learning is believed to contribute to the understanding of linguistic input (Cooke-Plagwitz, 2008; Liu, 2010).

\section{Enhancing non-verbal communications}

One of the ways to enhance non-verbal communication in 3-D MUVEs is the use of avatars in L2 interaction. In this study, the student teachers reported that they had had trouble expressing non-verbal cues such as facial expressions and body language. In practice, they might have failed to use the communicative features of avatars such as gestures and other types of body language. That is, they did not perceive that the constraints imposed by the lack of non-verbal cues in general CMC settings may be improved by the use of avatars in 3-D MUVEs. To solve this problem, the distance teachers should be made aware of inbuilt functionalities afforded by avatars, specifically gestures such as head shaking, hand shaking, and waving. If they are trained to take advantage of these non-verbal messages in various realistic scenarios, a sense of social presence may be promoted for the facilitation of speech communication (Allmendinger, 2010; Peterson, 2008; Svensson, 2003). In this case, they may experience a higher level of interaction with the distance learners, as noted by Peterson $(2005,2006)$.

Another way to enhance non-verbal communication in 3-D MUVEs is concerned with paralanguage. The participating teachers reported that more passion should be incorporated into their voices when teachers interact with the distance learners over the microphone; otherwise, the learners may lose interest in the oral lectures of the teachers. The teachers perceived that the interaction between themselves and the learners may have been promoted if the teachers had enhanced non-verbal cues, such as speech emphasis, 
volume and emotions. Although enhancing these kinds of non-verbal cues is encouraged in real-life teaching scenarios, this enhancement is particularly important in promoting synchronous computermediated interaction because the type of non-verbal cues are believed to increase social presence that tends to be low in synchronous online classes (Ko, 2012; Tu \& McIsaac, 2002). This finding adds to our understanding of enhancing L2 interaction in 3-D MUVEs. One pedagogical implication is that the student teachers could exploit default emotions, such as sad, embarrassed, and happy, in dealing with the problem of lacking paralanguage with regard to promoting L2 interaction in 3-D MUVEs.

\section{Conclusion}

This study examined the perceptions of student teachers of L2 interaction in relation to the learning and teaching of CFL, particularly in MUVEs. They perceived that the key to the success of fostering L2 interaction may be contingent on access to realistic scenarios and on the presence of non-verbal cues. More specifically, they thought that the interaction between themselves and the learners could be facilitated if the learners were exposed to more appropriate scenarios and objects, and if the users of avatars were made aware of taking full advantage of non-verbal resources, i.e., inbuilt gestures and emotions. Realistic scenarios and objects and non-verbal cues are thought to play an influential role in promoting L2 interaction in 3-D MUVEs. The findings of this case study suggest that the teachers considered this unique platform as a promising venue in which L2 interaction can be promoted for the acquisition of a foreign language.

The primary limitation of this study involves the bias of the student teachers. Since reflection reports and replies to interview questions are self-reported data, the pre-service teachers could consider how the researchers might have expected them to think and respond. Such bias could influence their reflections and responses. This research limitation can be overcome by incorporating data on actual interactions rather than just on teachers' memories of them in future studies.

Our research enables further studies on the topic of L2 interaction in the learning and teaching of Chinese as a foreign language in 3-D MUVEs. This study investigated the perceptions of teachers of the dynamic forces that mediated the interactions between the learners and the teacher, as well as the realistic scenarios. It may be beneficial to make research in this regard complete by examining students' perspectives as opposed to teachers' perceptions in future studies. In addition, further studies are needed to investigate the effects of using non-verbal resources, such as gestures, emotions, and paralanguage, on L2 interaction in 3-D MUVEs. The main aim of this study is to achieve an improved understanding of the complexities that are involved in the interactivity afforded by avatar-based virtual worlds.

\section{Acknowledgements}

Special gratitude is extended to the Department of Digital Education affiliated to the Institute for Information Industry in Taiwan, which provided technical support during the project.

\section{References}

Allmendinger, K. (2010). Social presence in synchronous virtual learning situations: The role of nonverbal signals displayed by avatars. Educational Psychology Review, 22(1), 41-56.

Chapelle, C. A. (1997). CALL in the year 2000: Still in search of research paradigms? Language Learning and Technology, 1(1), 19-43.

Chapelle, C. A. (2005). Interactionist SLA theory in CALL research. In J. L. Egbert \& G. M. Petrie (Eds.), CALL research perspectives (pp. 53-64). Mahwah, New Jersey: Lawrence Erlbaum Associates.

Chen, D. (2010). Enhancing the learning of Chinese with Second Life. Journal of Technology and Chinese Language Teaching, 1(1), 14-30.

Cheng, H.-J., Zhan, H., \& Tsai, A. (2010). Integrating Second Life into a Chinese language teacher training program: A pilot study. Journal of Technology and Chinese Language Teaching, 1(1), 31-58. 
Chow, A., Andrews, S., \& Trueman, R. (2007). A 'Second Life': Can this online, virtual reality world be used to increase the overall quality of learning and instruction in graduate distance learning programs? In M. Simonson (Ed.), Proceedings of the Association for Educational Communications and Technology International Convention (pp. 75-83). Bloomington, IN: Association for Educational Communications and Technology.

Clark, G. B. (2009). These horses can fly! and other lessons from Second Life: The view from a virtual Hacienda. In R. Oxford \& J. Oxford (Eds.), Second language teaching and learning in the Net Generation (pp. 153-172). Honolulu: University of Hawai'i, National Foreign Language Resource Center.

Coleman, D. W., Hickman, T., \& Wrege, A. (2007). Classroom practice: Virtual environments. In J. Egbert \& E. Hanson-Smith (Eds.), CALL environments: Research, practice, and critical issues (2nd ed., pp. 390-402). Alexandria, Virginia: TESOL.

Cooke-Plagwitz, J. (2008). New directions in CALL: An objective introduction to Second Life. CALICO Journal, 25(3), 547-557.

Cooke-Plagwitz, J. (2009). A new language for the Net Generation: Why Second Life works for the Net Generation. In R. Oxford \& J. Oxford (Eds.), Second language teaching and learning in the Net Generation (pp. 173-180). Honolulu: University of Hawai'i, National Foreign Language Resource Center.

Dalgarno, B., \& Lee, M. J. W. (2010). What are the learning affordances of 3-D virtual environments? British Journal of Educational Technology, 41(1), 10-32.

Dobuzinskis, A. (2011, April 21). More U.S. children adding Chinese to their ABCs. Reuters. Retrieved from http://www.reuters.com/article/2011/04/21/uk-mandarin-education-idUSLNE73K07720110421

Ellis, M., \& Anderson, P. (2011). Learning to teach in second life: A novice adventure in virtual reality. Journal of Instructional Pedagogies, 6(1), 1-10.

Ellis, R. (2000). Task-based research and language pedagogy. Language Teaching Research, 4(3), 193 220.

Emde, S. V. D., Schneider, J., \& Kötter, M. (2001). Technically speaking: Transforming language learning through virtual learning environments (MOOs). The Modern Language Journal, 85(2), 210225.

Erard, M. (2007, April 10). A boon to Second Life language schools: New Technology will allow highquality audio in a virtual world. MIT Technology Review. Retrieved from http://www.technologyreview.com/Infotech/18510/

Grant, S., \& Huang, H. (2010). The integration of an online 3D virtual learning environment into formal classroom-based undergraduate Chinese language and culture curriculum. Journal of Technology and Chinese Language Teaching, 1(1), 2-13.

Hadley, A. O. (2001). Teaching language in context (3rd ed.). Boston: Heinle \& Heinle.

Hampel, R. (2003). Theoretical perspectives and new practices in audio-graphic conferencing for language learning. ReCALL, 15(1), 21-36.

Hampel, R., \& Hauck, M. (2004). Towards an effective use of audio conferencing in distance language courses. Language Learning and Technology, 8(1), 66-82. 
Henderson, M., Huang, H., Grant, S., \& Henderson, L. (2012). The impact of Chinese language lessons in a virtual world on university students' self-efficacy beliefs. Australasian Journal of Educational Technology, 28(Special issue, 3), 400-419. Retrieved from http://www.ascilite.org.au/ajet/ajet28/henderson.html

Henrichsen, L. E. (Ed.). (2001). Distance-learning programs. Alexandria, Virginia: TESOL.

Hew, K. F., \& Cheung, W. S. (2010). Use of three-dimensional (3-D) immersive virtual worlds in K-12 and higher education settings: A review of the research. British Journal of Educational Technology, $41(1), 33-55$.

Holliday, L. (2007). Theory and research: Interaction and awareness. In J. Egbert \& E. Hanson-Smith (Eds.), CALL environments: Research, practice, and critical issues (2nd ed., pp. 163-170). Alexandria, Virginia: TESOL.

Kan, Y. H., Lan, Y. J., Hsiao, I. Y. T., \& Yang, S. J. H. (2010). A virtual Chinese language class in Second Life: Lessons learnt from a two-month pilot study. Paper presented at the 18th International Conference on Computers in Education, Putrajaya, Malaysia.

Khalsa, D. K., Maloney-Krichmar, D., \& Peyton, J. K. (2007). Theory and research: Interaction via computers. In J. Egbert \& E. Hanson-Smith (Eds.), CALL environments: Research, practice, and critical issues (2nd ed., pp. 19-28). Alexandria, Virginia: TESOL.

Ko, C.-J. (2012). A case study of language learners' social presence in synchronous CMC. ReCALL, 24(1), 66-84.

Kuriscak, L. M., \& Luke, C. L. (2009). Language learner attitudes toward virtual worlds: An investigation of Second Life. In L. Lomicka \& G. Lord (Eds.), The next generation: Social networking and online collaboration in foreign language learning (pp. 173-198). San Marcos, TX: CALICO Publications.

Liu, S. (2010). Second Life and its application in Chinese teaching and learning. Journal of Technology and Chinese Language Teaching, 1(1), 71-93.

Long, M. H. (1996). The role of the linguistic environment in second language acquisition. In W. C. Ritchie \& T. K. Bhatia (Eds.), Handbook of second language acquisition (pp. 413-468). New York: Academic Press.

Peterson, M. (2001). MOOs and second language acquisition: Towards a rationale for MOO-based learning. Computer Assisted Language Learning, 14(5), 443-459.

Peterson, M. (2005). Learning interaction in an avatar-based virtual environment: A preliminary study. PacCALL Journal, 1(1), 29-40.

Peterson, M. (2006). Learner interaction management in an avatar and chat-based virtual world. Computer Assisted Language Learning, 19(1), 79-103.

Peterson, M. (2008). Virtual worlds in language education. The JALT CALL Journal, 4(3), 29-37.

Peterson, M. (2010). Learner participation patterns and strategy use in Second Life: An exploratory case study. ReCALL, 22(3), 273-292.

Peterson, M. (2012). EFL learner collaborative interaction in Second Life. ReCALL, 24(1), 20-39.

Petrakou, A. (2010). Interacting through avatars: Virtual worlds as a context for online education. Computers \& Education, 54(4), 1020-1027.

Richards, J. C., \& Farrell, T. S. C. (2005). Professional development for language teachers: Strategies for teacher learning. Cambridge: Cambridge University Press. 
Short, J. A., Williams, E., \& Christie, B. (1976). The social psychology of telecommunications. New York: John Wiley.

Silverman, D. (2000). Doing qualitative research: A practical handbook. London: SAGE Publications.

Svensson, P. (2003). Virtual worlds as arenas for language learning. In U. Felix (Ed.), Language learning online: Towards best practice (pp. 123-143). Lisse: Swets \& Zeitlinger.

Tsui, A. B. M. (2001). Classroom interaction. In R. Carter \& D. Nunan (Eds.), The Cambridge guide to teaching English to speakers of other languages (pp. 120-125). Cambridge: Cambridge University Press.

Tu, C.-H., \& McIsaac, M. (2002). The relationship of social presence and interaction in online classes. American Journal of Distance Education, 16(3), 131-150.

Varli, O. (2009). An exploration of three-dimensional (3D) virtual worlds through ESL/EFL teachers' perspectives in Second Life. Unpublished master's thesis, State University of New York, Albany.

Vickers, H. (2009). Language teaching gains Second Life: Virtual worlds offer new methods to teach languages [Monograph]. Retrieved May 28, 2011, from

http://www.omniglot.com/language/articles/secondlife.php

Warschauer, M. (2000). The changing global economy and the future of English teaching. TESOL Quarterly, 34(3), 511-535.

White, C. (2003). Language learning in distance education. Cambridge: Cambridge University Press.

Xie, T. (2010). Tools for teaching Chinese in the virtual world. Journal of Technology and Chinese Language Teaching, 1(1), 59-70.

\section{Appendix}

The number of tutors and students in each pair as well as students' proficiency level

\begin{tabular}{|c|c|c|}
\hline Pair name & $\begin{array}{l}\text { Number of } \\
\text { tutors }\end{array}$ & $\begin{array}{c}\text { Number of students (proficiency } \\
\text { level) }\end{array}$ \\
\hline P1 & 2 & 3 (beginning) \\
\hline $\mathbf{P 2}$ & 2 & 4 (beginning 3 ; intermediate: 1 ) \\
\hline P3 & 2 & 3 (beginning) \\
\hline P4 & 2 & 3 (beginning) \\
\hline P5 & 2 & 6 (beginning) \\
\hline P6 & 2 & 6 (beginning) \\
\hline P7 & 2 & 3 (beginning) \\
\hline P8 & 2 & 3 (beginning) \\
\hline P9 & 2 & 1 (beginning) \\
\hline P10 & 2 & 1 (beginning) \\
\hline P11 & 2 & 1 (beginning) \\
\hline P12 & 2 & 1 (beginning) \\
\hline P13 & 2 & 2 (beginning: 1 ; low intermediate: 1 ) \\
\hline P14 & 2 & 1 (beginning) \\
\hline P15 & 2 & 1 (beginning) \\
\hline P16 & 2 & 4 (beginning) \\
\hline P17 & 2 & 4 (beginning) \\
\hline P18 & 2 & 3 (beginning: 2 ; intermediate: 1 ) \\
\hline P19 & 2 & 1 (beginning) \\
\hline
\end{tabular}




\section{Corresponding author: Jun-Jie Tseng, tseng913@gmail.com}

Australasian Journal of Educational Technology (C) 2013.

Please cite as: Tseng, J.-J., Tsai, Y.-H., \& Chao, R.-C. (2013). Enhancing L2 interaction in avatar-based virtual worlds: Student teachers' perceptions. Australasian Journal of Educational Technology, 29(3), $357-371$. 